\title{
THE INFLUENCE OF THE FOREIGN LANGUAGE ON THE PERSON VALUE ORIENTATIONS FORMATION: THEORETICAL ASPECTS
}

\author{
Marchuk Vladimir ${ }^{1}$ \\ Stadnik Nadiya ${ }^{2}$
}

DOI: http://dx.doi.org/10.30525/978-9934-571-27-5_29

Abstract. The purpose of the article is to highlight the fact that at the present stage of the person value orientations formation by means of foreign language the main condition is to provide the needs of Ukraine in highly qualified specialists who will be able to communicate professionally in a foreign language with foreign colleagues in different spheres who will be able to think creatively, navigate and adapt to rapid changes in modern market relations, to apply the latest information technologies.

Investigating the problem of the value orientations formation, the researchers note that their range can be determined by the range of interests of the individual, in the breadth of his connections with the outside world. Taking into account the power of motivational influence of value orientations on the human consciousness, value orientations on work, family, education, public activity and other areas of self-assertion of the individual are allocated.

Of particular interest are studies in which the essence, structure, content of value orientations, their functions in the life of a person and society are determined, typology of both the value orientations and individuals is conducted on the basis of the nature of their value orientations. After all, without finding out the essential properties of value orientations, which, according to many researchers, is an important component of the internal structure of the individual, it will not be possible to find out their determinant role in the transformation processes.

System of value orientations is an important element of the value relation of a person to the surrounding reality. Value orientation, is a selective

\footnotetext{
${ }^{1}$ Candidate of Pedagogical Sciences,

Associate Professor at Foreign Languages Department,

Bila Tserkva National Agrarian University, Ukraine

${ }^{2}$ Candidate of Pedagogical Sciences,

Associate Professor at Preschool Education Department of Pedagogical Institute,

Borys Grinchenko Kyiv University, Ukraine
} 
attitude of man to material and spiritual values, a system of attitudes such an attitude, beliefs, and preferences that affect the behavior of the individual. At the same time, this means the positive or negative significance of objects of the surrounding world for an individual, a class, a social group, society as a whole, which manifests itself through the sphere of life, interests, needs, and social relations. As a result of social practice, as noted by researchers, value orientations of an era are involved in shaping the type of personality, its behavioral and mental skills, and in this capacity permeate the whole culture, all universals of this culture.

\section{Introduction}

The origins of the theory of values should be sought even in the ancient pedagogical concepts. The focus of pedagogical doctrine is not only nature, but also the person who began to explore, to study, to know itself and its thinking. There was another point of view according to which morality is a product of a society or an individual, and, therefore, there is no universal and unified morality and political ideal as values, morality and law have a relative character. By affirming and recognizing the relativity of morality and the ideal, the teachers created the basis for understanding the relativity of values. There are values and norms that represent the universal good (the highest goodness) and justice. Virtue is considered such a value and norm. The main meaning of this word is primarily due to moral perfection. To be "virtuous", "perfect", it is necessary to have the normative knowledge of what "good" is, what is "evil." The notion of "goodness", "virtue" in the broad sense, as the concept of "good", that is, as the highest value, which is the moral perfection of man, achieved by the embodiment of high moral goals "in the best way."Man as a reasonable living creature, which is inherent in the mind and language. The soul of a person is, above all, its thinking, in comparison with which volitional, emotional and other elements of human activity are secondary.

As for a person, its value orientations are determined by social life in the policy. Benevolence and a person who is guided solely by the mind, by which it organizes its behavior and coordinates it with the natural flow of things in which the logos, the mind of the world manifests itself.

The entry of Ukraine into the European Commonwealth requires the adaptation of the Ukrainian national economy to the new conditions of management, new economic relations, and the expansion of international 
relations in various fields. The withdrawal of our state at the forefront of the progress of human civilization will depend on how quickly and successfully the state system of higher education can prepare specialists of a new formation that will be able to think creatively, navigate and adapt to rapid changes in modern market relations, apply the latest information technologies.

\section{Analysis of research and publications.}

The question of value orientations in the scientific literature is not new, it was researched by such scholars as A. G. Alexandrov, V. P. Annenkov, A. M. Arkhangelsky, A. O. Bandura, V. V. Marchuk, I. D. Bekh and others.

Value orientations as a scientific problem attract the attention of a wide range of scientists of different fields of scientific knowledge. It is considered in close connection with the life goals of the individual, the way of life, needs, interests, psychological settings, etc. Such a wide range of issues, tangent to which the essence and character of value orientations are studied, makes it possible to distinguish, at least, several areas of studying this phenomenon.

Investigating the problem of the value orientations formation, the researchers note that their range can be determined by the range of interests of the individual, in the breadth of his connections with the outside world. Taking into account the power of motivational influence of value orientations on the human consciousness, value orientations on work, family, education, public activity and other areas of self-assertion of the individual are allocated.

Of particular interest are studies in which the essence, structure, content of value orientations, their functions in the life of a person and society are determined, typology of both the value orientations and individuals is conducted on the basis of the nature of their value orientations. After all, without finding out the essential properties of value orientations, which, according to many researchers, is an important component of the internal structure of the individual, it will not be possible to find out their determinant role in the transformation processes.

For the classification of the structural components of the system of value orientations, the cultural approach is also used, that is, the structural components of the system of value orientations are classified on the basis of a certain type of culture, guided by the provision that the culture itself is a set of certain values and their practical implementation in various spheres of human life.

Depending on the types of culture, the following main types of value orientations are distinguished: political culture, which includes high political 
consciousness and activity, the ability to understand the essence of running political events, to respond correctly to them and, accordingly, to it, political value orientations; moral culture and moral value orientations, based on which the focus is on the coordination of individual individuals of their behavior with the interests of other people and society as a whole, knowledge and observance of social and universal moral standards of conduct, to overcome the so-called "double" morality (morality "for self "and morals" for others); aesthetic culture and, in accordance with it, aesthetic value orientations based on the developed aesthetic perception, the ability to give an estimation of aesthetic in the phenomena of reality, the desire to master the aesthetic culture of the past and modern stages of the development of society [6].

System of value orientations is an important element of the value relation of a person to the surrounding reality. Value orientation, is a selective attitude of man to material and spiritual values, a system of attitudes such an attitude, beliefs, and preferences that affect the behavior of the individual. At the same time, this means the positive or negative significance of objects of the surrounding world for an individual, a class, a social group, society as a whole, which manifests itself through the sphere of life, interests, needs, and social relations. Criteria for assessing this significance in moral norms and principles, ideals, goals, installations. As a result of social practice, as noted by researchers, value orientations of an era are involved in shaping the type of personality, its behavioral and mental skills, and in this capacity permeate the whole culture, all universals of this culture.

Value orientations are at the heart of the human worldview, of its moral, political, aesthetic beliefs and tastes, and determine its behavior. Given their importance for human behavior, value orientations are determined as important elements of the internal structure of the individual, embodied in the life experience of the individual, all the totality of his experiences, distinguishing significant, essential for a given person from insignificant, immaterial. The formed value orientations are a kind of "axis" of consciousness, which ensures a person's solidity and manifests itself in a certain type of behavior, in the interests, needs, beliefs.

There are developed, stable, consistent, and undeveloped, unstable, contradictory value orientations in scientific literature. The first type of value orientations, - notes, in particular, O.G. Zdravomyslov - is a sign of man's maturity, the indicator of its sociality, this is - the prism of perception of not only the external, but also the inner world of the individual, which deter- 
mines the connection between consciousness and self-awareness, the psychological basis for solving both in the individual as well as in the general public the question of the meaning of life, due to which the integration of a set of value orientations into a somewhat integral and peculiar, is characteristic for this person [3].

Developed, sustained value orientations determine such qualities of a person as integrity, reliability, loyalty to certain principles and ideals, the ability to volitional actions for their achievement, and activity. And, conversely, unstable, underdeveloped, contradictory value orientations are the cause of inconsistency in human behavior, a sign of its infiniteness, uncertainty of purpose, meaning of life, etc.

Value orientations are also considered as a system of social values perceived by the individual, which is one of the factors that determine the movement of a person from an event to an event in the direction of the future. Planning for the future, drawing out specific events - plans and goals, a person goes first of all from a certain hierarchy of values that is in her consciousness. Guided by a wide range of social values, the individual chooses the ones that are most closely related to his dominant needs. Subjects of these needs, being conscious perceptions, become its leading values of life. The selective orientation of a person to certain values is reflected in the hierarchy of value orientations of a person. Therefore, the value orientations of a person are considered in close connection with the life perspective, life goals and plans.

Value orientations represent a higher level of the dispositional structure of the individual and are interpreted by researchers as an orientation towards the purpose of life and the means of achieving them. On this basis, one can distinguish the orientation, the object of which is the person himself, its socially significant qualities and ways of their reproduction and development. No less important feature of these orientations is that they are implemented in the social sphere. All this, according to V.A. Matusevich, gives the right to define them as social orientations.In the modern period, the system of values has changed qualitatively [7]. And when a person, while paying tribute to traditional value orientations, may try to obtain higher education, devoting his work activity to a certain period of his life, but at the same time not to enjoy learning, not to show interest in the process of knowledge - characterizes various contradictory elements of its value orientations. There are many examples of such contradictions. The basis of 
the allocation of elements of the system of value orientation structure-forming factor may be the idea of an ideal (the ideal of society, the ideal of personality, group, class, etc.). Part of researchers, defining the structure of the system of value orientation, based on the concept of the meaning of life, the need for self-determination, self-assertion. Every person has a sense of life, regardless of whether he realizes it or not, reflects adequately or inappropriately about his life. You can speak as much as you want about your high vocation, but to objectively judge the meaning of human life is necessary only in the direction of its social activity, which is encouraged by its value orientations.

In close relationship with the ideological-political, moral-aesthetic culture and corresponding value orientations, an ecological culture is allocated and, accordingly, it is ecological value orientation; ecological culture involves the rational use of natural resources, a culture of behavior in recreation areas and others; culture of labor and, accordingly, value orientations in labor activity, which accumulate in itself all other value orientations.

Investigating the problem of forming a person, I.S. Kon states that "orientation is a whole set of systems in the light of which the individual (group) perceives the situation and chooses the appropriate way of action" [4]. V.O. Tyurina in general does not consider the concept of "value orientation", but believes that "in the case of any need and situation of its satisfaction with the subject there is a specific condition that can be characterized as readiness, as its installation to the implementation of a certain activities aimed at satisfying its actual needs" [9].

Considering the concept of "value orientation" as rather complicated in its structure formation, in its analysis it is necessary to focus on various aspects of the content: in a sociological context, for example, value orientation can be associated with the facts of the actual behavior of the individual, with the direction and content of his social activity, with the firmness of her life goals, and so on. Basic value orientations are those that characterize the general specific features of the individual in a particular social class (group), the type of basic culture of the person, the main features of the national character, that is, it is nothing but the process of forming a person of a certain social type, a certain period of development of society.

In psychological studies, we also encounter different definitions of this category. Yes, S. K. Nartova-Bochevar believes that value orientations are an internal regulator of human activity, which forms the basis of its self-ac- 
tualization. G.L. Budinite and T.V. Kornilov, investigating the process of formation of "personal values" and their role in self-regulation of the person's relation to the surrounding reality, found that exactly such values and value orientations are a specific form of the functioning of semantic neoplasm's in personal structures. Psychologist's value orientations of the person considered in close relationship with other its qualities and features connect the process of their formation with the dynamics of development of consciousness and self-awareness, the motivational sphere, settings, and others. Scientists are trying to reveal the psychological "roots" of the formation of personal values, and, consequently, value orientations, to find the regularities of this process. Considering personal values as an indicator of a certain level of personality development, the level of its self-consciousness, scientists admit that due to value orientations there is an indirect transition to a higher level of personal neoplasm's, acting as regulators of the behavior and behavior of the individual.

At the present stage, the personality value orientations formation by means of a foreign language is the main condition for ensuring the needs of Ukraine in highly skilled specialists who will be able to communicate professionally in a foreign language with foreign colleagues in various spheres. On the modern stage of the personality value orientations formation by facilities of foreign language a main condition is to provide the requirements of Ukraine in highly skilled specialists which will be apt at professional intercourse in foreign language with foreign colleagues in different spheres. Such social order finds a direct reflection in programmatic requirements in relation to the level of the foreign language possessing by the students of higher educational establishment, which foresees achievement of agrarian type higher educational establishment of such level, development of foreign skills and abilities, which would allow to carry out the direct socializing with foreign partners in professional activity both in a verbal and in a writing form.

The sphere of education in the most degree determines the level of society development and becomes national priority in the most world countries. Therefore National Doctrine of education development in Ukraine to the key tasks puts modernization of education in accordance with the requirements of the Ukrainian state system of XXI century, formation of the personality value orientations on the modern stage, national development and national safety, gradual transition from genesial, authoritarian educa- 
tion to the formation of innovative, humanism type. This transition is the necessary consequence of deep processes which are predefined by public changes - transition from industrial to informative society [8].

The radical changes that have taken place in the national system of higher education in Ukraine initiated by the process of integration of the country into the European space of higher education, led to the development of a new typical English language teaching program for professional communication. Based on the principles of internationalism, democracy, equality and innovation, this program aims to form new value orientations, promote student mobility and their competitiveness in the labor market, and enhance the attractiveness of higher education in Ukraine by providing a transparent and flexible system for teaching and learning foreign languages. The goals and objectives of the program are in line with the objectives set out in the European Language Education Recommendations (ELER) and with the goals set out in the Ukrainian qualification standards, namely the need for further intensification of the processes of studying foreign languages in the interests of mobility, more effective international communication [2].

The purpose of the paper is to highlight the role of a foreign language in the process of personality value orientations formation at the present stage of development of our society.

\section{Presenting main material.}

Modern content of education is multi component. It includes not only knowledge, but also the ways of practical activity, creative approach, and value orientations of the individual. By preserving the achievements in the foundation of higher professional education, there is a need to reorient the educational process to form in students the desire and ability to independently acquire knowledge from different sources of information. Therefore, it is important to apply the personality of orientated pedagogical technologies. Their features are education and upbringing, the formation of value orientations with the maximum possible use of individualization (taking into account in the process of learning the individual characteristics of students in all its forms and methods).

In the "Pedagogical encyclopedia" individualization is determined as "organization of educational process, at which the choice of methods, receptions, rate of studies takes into account the individual differences of students, level of development of their capacities for studies", conditioning 
for self-development and self-training, critical and intelligent determination of the possibilities and vital aims. Such type of studies is based on a dialog, design of situations of choice, free exchange by ideas, analysis of success or mistakes [1].

That is why higher education in our country is not only a means of training specialists to various fields of activity, but also a stage of development of value orientations of a highly skilled person. As Vasyl Kremen noticed, as many Ukrainian citizens as possible will be able to obtain a qualified higher education, because the future of the country depends on the level of intellectualization. Higher education should become a mandatory stage in human life [5].

School education requires high school teachers to update the content and techniques that form the philosophy of the world, the ability to study independently, think critically, use the computer, the ability to self-identify and express oneself, necessary for social adaptation, conscious choice of one's own life.

\section{Findings}

The implementation of state policy in the field of vocational education contributes to the improvement of professional training of specialists, the opening of new types of higher education institutions, their entry into educational research facilities, and the expansion of the range of educational services.At the same time, in line with the prospects for the development of the economy and the social sphere, the need for training of qualified specialists with knowledge of a foreign language is growing.

The modern system of preparation of students of agrarians in higher educational institutions of Ukraine is based on the branch standards of higher education of the Ministry of Education and Science of Ukraine It is they who determine the educational qualification characteristics of graduates of the relevant training requirements $(\mathrm{EQC}$ - educational qualification characteristic).

The full range of skills which must be mastered by a student-agrarian during a course of study at an institution of higher education is divided into five components of professional qualities: plan-content, organizational, motivational, supervisory, coordination. They include such skills as:

1) Planned content: analyze the market situation, the state and dynamics of demand, develop business plan projects, plan the development of the organization and its competitiveness, plan resources (material, financial, 
labor), develop tactical and operational plans of current activities, use the office equipment and tools of the World Wide Web.

2) Organizational skills: to combine all kinds of resources, to organize collective work in order to achieve the goals of the organization, to choose and implement rational forms of organization of management, to ensure an adequate level of quality and competitiveness of products, to strengthen international relations, to participate in foreign economic activity, to work with personnel, to form a team and to manage it, to support organizational culture.

3) Motivational skills: to use effective systems of motivation for formation and remuneration, to implement managerial decisions, to allocate powers, to maintain a favorable socio-psychological climate in a team, to influence subordinates.

4) Controlling skills: quickly control the availability of resources, adhere to technologies, monitor payments with suppliers and consumers, monitor implementation of decisions and support discipline, prepare activity reports, monitor occupational safety and safety equipment.

5) Coordination skills: to establish and support the relationship with the external environment, to keep records, to regulate the behavior of personnel in the process of enterprise's activity [8].

Without diminishing the importance of mastering of the listed functional skills by future specialists, today's education aims are:

- Improvement of the methodology of formation of intellectual culture, skills of self-organization of thinking, content communication;

- increasing the level of professional training of students to world-class;

- acquaintance of students with the basics of entrepreneurial activity, taking into account the specifics of the cultural and historical realities of the Ukrainian mentality.

However, mastering a specialty at a professional level is impossible without the knowledge of a foreign language and the secondary training of students of non-native specialties and is one of the important components of higher education, which is currently being implemented within the discipline "Professional foreign language".

Until recently, the notion of "foreign language" as an educational discipline was generally accepted for the whole system of education in our country, regardless of the specifics of the purposes of foreign language training. Such a unified purpose of this discipline, according to didactics, transmitted 
the idea of continuity in the system of secondary and higher education. At the same time, the analysis of typical foreign language programs for non-native specialties shows that in the period from the early 60 's up to the end of the 1990's the teaching of foreign languages in non-language higher educational institutions was practically conducted in the context of student's professional training and, accordingly, little specific content and provided for different from the school teaching methods.

To the conclusion that the content of teaching foreign language students of non-language higher education institutions should be different, also came from foreign colleagues. In the early 60's in western countries there are practical developments of English for students of different non-language specialties, and in the teaching-methodical literature the term is introduced "English for special Purposes", which included such concepts as English for Occupational Purposes, English for business communication and English for Academic Purposes.

According to UNESCO analysts, the XXI st century should become a century of highly skilled professionalization of future specialists. The modern world, which is constantly updated, leads to changes in the education system, to the formation of new value orientations of the individual, envisaging enrichment of the existing content of education professionalization [2].

Knowledge of future specialists of a foreign language becomes especially relevant today, when the aspiration of Ukraine to enter the international economic community requires the presence of a large number of specialists, people who speak foreign language.

The development of a means of forming readiness for communication in a foreign language by future specialists of a higher non-formal educational institution requires consideration of the following issues:

- Identification of the structural components of the specified readiness;

- determination of indicators and levels of formation of each structural component of readiness to communicate in a foreign language.

The analysis of scientific works on the considered problem showed that for today considerable theoretical and experimental material has been accumulated concerning the formation of the readiness of the individual for various types of activities (O. Bykova, O. Boyko, S. Vorobyov, V. Ivashkovsky, P. Matvienko, N. Moiseyuk, K. Magagon, O. Tomas, S. Radchenko and others). Scientists use different approaches to solving this problem, offering a system of diverse tasks, developing lingvodidactic directions of readiness 
for one or another type of activity. However, in each research study, the components, indicators and levels of formation of the mentioned readiness are not considered.

Indeed, before forming these or other abilities, the readiness for communication in a foreign language in particular, it is necessary to identify and analyze the content of this concept, its structural components and their features, to reveal to students the level of knowledge of the language, speech skills and skills.Studies in the field of psycholinguistics (M. Zhin'kin, O. Leontiev, O. Luria) suggest that for a full-fledged communication in a foreign language, a person must have certain skills: quickly and correctly orient in the conditions of communication in a foreign language, plan correctly to find adequate means for transmitting its contents. The process of communicating in a foreign language is seen by scholars as creative, since different people submit the same idea in different ways.

In the process of teaching a foreign language, elements of future professional activities are combined with speech phenomena, which act not only as a means of communication, but also as a way to familiarize students with a new reality for them. As a result, along with the acquisition of a foreign language, the acquisition of professional knowledge and the formation of the ability to understand the mentality of the carriers of another language takes place, which in turn positively influences the person value orientations formation. From the socio-psychological point of view, the student's personality must be ready for the acquisition of new information and intercultural communication and mutual understanding. This readiness is manifested in the following qualities of a future specialist:

- awareness of one's identity and its presentation, that is, the ability of the individual to understand that the actual perception of colleagues in business is conditioned by professionally significant factors and collective mentality; it also means the ability of an individual to show his world to foreign speakers in a foreign language;

- role distance: this is the ability of the individual abstract from their own position, role, look at it from the side, while realizing that there are other perceptions of the world and that the stereotypes of another world are as natural to him as their own;

- empathy: the ability of the individual to enter the situation of another person (in our case, the representative of another professional community), an attempt to understand it; the development of this quality plays an import- 
ant role in affective, rather than cognitive processes, because outside the linguistic environment this occurs through texts, films, pictures;

- the ability of the individual to not be afraid to meet with the representative of another country, not to avoid it, but to come into contact, withstanding conflicting expectations and expectations. Therefore, it is in the classroom with a foreign language that it is necessary to give students such an opportunity to meet with a representative of another culture and develop the ability to analyze and discuss their perceptions.

As you know, language is not only a system of characters used by humankind, which is a way of thinking, man expressing his feelings, transitions. The language objectifies the self-consciousness of personality, the spiritual life of all people, and the peculiarities of his mentality. To better understand the nature of one or another people, to penetrate into its depths, considered $\mathrm{K}$. D. Ushinsky, it is necessary to learn the language of this people. Value orientations of young people in one language or another, in our opinion, are the spokesperson for her outlook, self-consciousness. The inclusion of personality in new social relations is complex and ambiguous, and this process of integration also has a multi-faceted nature: it affects the worldview aspects of the spiritual life of an individual, his political priorities, stability or mobility, the dynamism of stereotypes of thinking, transforms an individual into a situation of restructuring the entire structure thinking.

Characteristic indicators of the language orientations of youth indirectly reflect the crisis elements in the general processes of social development at this stage, as well as in relations between the state and certain social groups, in this case, young people. Differences in the language orientations of young people indicate, moreover, that there are contradictions in the motives of the behavior of young people of various social and regional groups, and, consequently, on internal contradictions in the youth environment.

As evidenced by the historical development of society, transitional, crisis periods are always accompanied by deep psychological crisis phenomena, first of all it concerns the youth category of the population. As a rule, these phenomena have different forms of manifestations - from confusion, disappointments, pessimism to clearly expressed rebellion, open nihilism. Sometimes in such a crisis a young person who has not yet fully formed a vital credo chooses the easiest way - a way of balancing, waiting, but this period does not last long. Research shows that the number of patients of social psychiatrists has increased considerably in recent years. One of 
the reasons for this is the aggravation of the contradictions between the demands and aspirations of the individual, his subjective abilities and the lack of socio their conditions for their implementation, which ultimately leads to a psychological (and sometimes even psychological) disruption. As a rule, it is precisely such youth in our society (as, incidentally, and in other states that have passed a similar path of development), it adds to the number of drug addicts, suicides, terrorists, killers who do not already have the ability to self-control, self-regulation and self-esteem. This is one of the forms of manifestations of the internal crisis of personality, caused by the instability of social development, and, consequently, the system of values.

Particularly difficult to us is the definition of value orientations in the structure of pedagogical consciousness. The notions of "values" and "value orientations" are used synonymously. Some researchers believe that value orientations act as "peculiar substitutes for values". Obviously, values are related to social consciousness, and value orientations characterize individual consciousness.

We associate pedagogical consciousness with an individual consciousness, so we use the notion of "value orientation". Under value orientations, we understand the social deterministic and fixed in the psyche of the individual's focus on the purpose and means of action. Accordingly, value orientations are divided into terminal (value-purpose) and instrumental (value-means). In relation to value orientations, there are two distinct approaches: sociological and psychological.

The psychological approach to the concept of "value" lies in the fact that they are considered in terms of special significance for each member of the social group. Valuable orientations are studied within the framework of the study of the motivational sphere of human consciousness. Attribution of this or that object to value is expressed in this case in its ability to meet the needs, interests and goals of man. The concept of "value" - is a subjective reflection in the individual's consciousness of certain specific properties of objects and phenomena of the surrounding reality. Thus, a value-added approach to the phenomena of the surrounding reality is that all of them (including the actions of people) are reflected in the minds of individuals as values, that is, from the point of view of their ability to meet human needs. Proceeding from the fact that the value of objects and phenomena and their content for a person is that determines behavior, one can say that values are determined by a broad motivation of human behavior, representing a pivotal form of the motivational structure of the individual. 
In contrast to the general philosophical approach, the distinctive feature of the psychological approach to the problem of values is the differentiation of value objects. They are subdivided according to the meaning of the same species, group, class of values. The concretization and hierarchy of values are carried out. In the motivational sphere of pedagogical consciousness values play the role of a peculiar evaluation activity, which involves the perception and assimilation of the objective semantic side of the subject, on the one hand, and the evaluation of its properties in terms of subjective significance for the individual, matching his needs and interests - from another Thus, values are the connecting link between meaning and meaning. As a result of evaluative activity, awareness of the object of social is realized reality and thus forms a special kind of relationship to it - a value relation (V.N. Myasyshev, V.P. Tugarinov).

Valuable orientations - one of the structural entities of the consciousness of a mature person. Valuable plants influence the person's disposition (V.A. Poetry), its installation (Yu.M. Zhukov), motives (V.M. Aseev), interests (I.V. Dubrovin, B.S. Kruglov) and even determine the meaning of life (K. Obukhovsky). Characteristic features of the influence of value orientations on the behavior and activity of the individual are manifested in the fact that "valuable orientations, referring to the meaningful structures of consciousness, affect behavior mediated and function as ways to rationalize behavior".

Valuable orientations in the structure of pedagogical consciousness are subjected to multiple and very substantial transformations. This is a logical result of human life, changes in the relationship between man and the world, other people, society. As a result, changes in the internal conditions on the basis of the formed psychological mechanism of differentiation come into effect, actualizing one or another of the values. As the person acquires a life experience, not only all new and new aspects of being, but also a more or less profound rethinking of life, occur in front of it. This process of rethinking that passes through the entire human life forms the most secret and basic content of its inner consciousness, which determines the motives of its actions and the inner meaning of the tasks it, performs in life. Valuable orientations, as we have already said, are the unity of three components: cognitive, emotional and behavioral.

All this is formed in adolescence, where the process of compilation of the hierarchical system of valued personality orientations should be considered. Until the beginning of pedagogical formation in the university, there 
already exists a peculiar system of value orientations gradually transformed under the influence of education and vocational education, one of the most important educational functions of which is the translation of values. Pedagogically important qualities of the personality of the future agrarian are nothing but a system of instrumental value orientations of the individual. Pedagogical activity is a significant stimulus that results in the content of value orientations.

Valuable orientations of the individual, being a component of the internal structure, the outlook of the individual, are in a dialectical relationship with the interests, needs, attitudes, motives of activity, may be adequate in relation to the value orientations of society, the essential, objective value phenomena of spiritual culture, themselves can act as factors and determine the system of values of a certain social group, class, society as a whole.

\section{Conclusions}

Consequently, the theory of value is already forming in pedagogy, although axiological judgments are included only as a component in the structure of the pedagogical categorical apparatus. However, it should be emphasized that already in this structure used a separate concept of "value". In the end, it is precisely on this date that the name "axiology", the science of values, began much later.

The axiological provisions of pedagogy have become the basis for further development of the value-based approach of man to the surrounding world. The aspects of the evaluative view of human being, in particular, such as ethical, aesthetic, utilitarian, practical, etc., were distinguished, on the basis of which the teachers tried to answer the question of what is "good", "truth", "benefit", "beauty", etc.

The concept of value in general relates to everything, denoting an identical function (realization of opportunity) in relation to the different content in each particular case. The value, existentially constructed by its derivative character from the absolute knowledge and love, can again be the object of cognition and the meaning of the train, first of all - from the person. Due to this secondary generalization, value can be determined. At the same time, knowledge must be directed primarily to the object, not inside it, subjective values. Therefore wisdom is not only in knowledge, but also in love. It is in this that the decisive and fruitful (good) message of a person is formed, which causes its development as a person. 
Consequently, based on the foregoing, one can conclude that a foreign language provides the formation of value orientations of personality and communication between those who communicate, because it understands it as the one who informs the information, encoding it in the meanings of words, Selected for this purpose, and the one who receives this information, encoding it, that is, deciphering these values and changing on based on this information its behavior. The person who addresses the information to another person and the one who accepts it, to realize the goals of communication and the common activities should use the same system of codification and decoding of values, that is, to speak "in one language".

\section{References:}

1. Navolokova, N.P. (2012) Entsyklopediia pedahohichnykh tekhnolohii ta innovatsii [Encyclopedia of pedagogical technologies and innovations]. Kharkiv: Vyd. hrupa "Osnova". (in Ukrainian).

2. Nikolaieva, S.Yu. (Eds.). (2003) Zahalnoievropeiski rekomendatsii z movnoi osvity: vyvchennia, vykladannia, otsiniuvannia [European Recommendations on language education: study, teaching, evaluation]. - Kyiv: Lenvit. (in Ukrainian).

3. Zdravomyslov, A. H. (1986) Potrebnosty. Ynteresy. Tsennosty [Needs. Interests. Values]. Moscow: Polytyzdat. (in Russian).

4. Kon, Y. S. (1967) Sotsyolohyya lychnosty [The Sociology of Personality]. Moscow: Vysshaya shkola. (in Russian).

5. Kremen', V. H. (2005) Osvita i nauka v Ukraini - innovatsiini aspekty. Stratehiia. Realizatsiia. Rezultaty [Education and Science in Ukraine - Innovative Aspects. Strategy. Realization. Results]. - Kyiv. : Hramota. (in Ukrainian).

6. Marchuk, V.V., \& Stadnik, N.V. (2016). Vzaiemozviazky tsinnisnykh oriientatsii i sotsialnoho seredovyshcha [Interrelationships between value orientations and social environment]. Tendentsii ta perspektyvy rozvytku nauky $i$ osvity $v$ umovakh hlobalizatsii: materialy XIII Mizhnarodnoi naukovo-praktychnoi internet-konferentsii (Ukraine, Pereyaslav-Khmelnitsky, October 27-28, 2016), PereyaslavKhmelnitsky: DVNZ "Pereiaslav-Khmelnytskyi derzhavnyi pedahohichnyi universytet imeni Hryhoriia Skovorody" (Volm. 18), (pp. 175-177). Retrieved from http://confscience.webnode.ru (in Ukrainian).

7. Matusevych, V. A., Ossovskyy V. L. (1982) Sotsyal'naya mykrosreda y vybor professyy [Social microenvironment and the choice of profession]. Kyiv: Nauk. Dumka. (in Ukrainian).

8. Natsionalna doktryna rozvytku osvity Ukrainy v XXI stolitti (2001) [The National doctrine of the development of Ukraine's Education in the 21st century]. Osvita Ukrainy, no. 29, pp. 4-6. (in Ukrainian).

9. Tyuryna, V. A., Nauchytel' E. D. (1998) Tsennostnye oryentatsyy [Value judgments]. Kyiv: OOO "Mezhdunar. fyn. ahenstvo". (in Ukrainian). 